\title{
UV Analytical Method Suitability for Investigation of BCS Class 2 Biowaivers: Ibuprofen Case
}

\author{
Noelia L. Gonzalez Vidal11,* and M. Esther Gil Alegre ${ }^{2}$ \\ 'Cátedra Control de Calidad de Medicamentos, Departamento de Biología, Bioquímica y \\ Farmacia, Universidad Nacional del Sur, Bahía Blanca, Argentina \\ ${ }^{2}$ Departamento de Tecnología Farmacéutica, Facultad de Farmacia, Universidad Complutense de Madrid, Madrid, España
}

\begin{abstract}
Biowaivers are scientifically justified for immediate-release oral dosage forms containing BCS Class 2 drugs. Therefore, a comparison of in vitro dissolution profiles via similarity factor calculation is expected. If a difference greater than $10 \%$ cannot be detected by the analytical method, then the $f_{2}$ similarity factor will not detect any differences between profiles. The aim of the present study was to evaluate the sensitivity of UV measurements of a Class 2 drug, ibuprofen, at the three physiological $\mathrm{pH}$ values of biowaiver analysis and at the different wavelengths according to USP and Ph. Eur. The slope of the calibration curve and the discriminant capacity were calculated to evaluate the sensitivity of each method. It was concluded that at $264 / 272 \mathrm{~nm}$ (identification Ph. Eur. and USP wavelengths), the analytical method is not suitable for ibuprofen biowaiver investigation, while at 220/221 nm (USP dissolution test), the UV method has adequate sensitivity.
\end{abstract}

\section{INTRODUCTION}

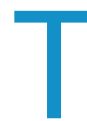
he Biopharmaceutics Classification System (BCS) guidances $(1,2)$ allow a waiver of in vivo bioequivalence studies for immediate-release oral dosage forms containing BCS Class 1 drugs (rapidly dissolving and with similar dissolution profiles to the reference product at $\mathrm{pH}$ values of $1.2,4.5$, and 6.8). Further discussions and subsequent publications $(3,4)$ recommend that biowaivers can be extended to BCS Class 2 weak acids (high solubility at $\mathrm{pH} 6.8$ but not at $\mathrm{pH} 1.2$ or 4.5 , high permeability) if the multisource product is rapidly dissolving at $\mathrm{pH} 6.8$ and its dissolution profile is similar to that of the reference at the three $\mathrm{pH}$ values. Ibuprofen (IBU) is a Class 2 drug (5); therefore, biowaivers for its immediate-release dosage forms are under investigation $(6,7)$. Besides, this NSAID is one of the most-used anti-inflammatory drugs, with a large number of different formulations available.

Dissolution profile similarity may be determined using the $f_{2}$ factor. When two profiles are identical, $f_{2}$ has a value of 100 . An average difference of no more than $10 \%$ at any sample time point of the profiles may be acceptable, and this represents a similarity factor of 50 . The dissolution profile of a test batch is therefore considered similar to that of the reference product if the $f_{2}$ value is not less than 50 (8).

The ability of the in vitro dissolution test to detect differences is of great importance for biowaiver definitions. Thus, the sensitivity of the analytical method used to measure the dissolution samples is also of great importance. The USP dissolution test for IBU immediaterelease tablets uses quantification by UV spectrophotometry at the wavelength of maximum absorbance (about $221 \mathrm{~nm}$ ), while HPLC with UV detection at $220 \mathrm{~nm}$

${ }^{*}$ Corresponding author. is recommended for IBU oral suspensions (9). According to USP (9) and Ph. Eur. (10), IBU is identified by UV absorption at about 264 and $272 / 273 \mathrm{~nm}$ in $0.1 \mathrm{~N}$ sodium hydroxide. It is known that absorbance wavelength and sensitivity of measurements can vary according to the solvent in which the analyte is dissolved. Investigation of the possibility of biowaivers for IBU was carried out by Alvarez et al. (7) using UV spectrophotometry according to Ph. Eur.

The purpose of the present study was to evaluate the sensitivity of UV measurements of a Class 2 drug, IBU, at the three physiological $\mathrm{pH}$ values and different wavelengths according to USP and Ph. Eur., to verify the suitability of the analytical method for biowaiver studies. The sensitivity of each method was evaluated through the slope of the calibration curve and the discriminant capacity.

\section{MATERIALS AND METHODS \\ Reagents}

IBU Ph. Eur. bulk drug (99.8\% purity, 0.100\% humidity) was purchased from Guinama (Valencia, Spain). Hydrochloric acid, glacial acetic acid, potassium chloride, sodium acetate trihydrate, sodium hydroxide, and monobasic potassium phosphate were purchased from Panreac (Barcelona, Spain). High purity deionized water was obtained from a Milli-Q purification system (Millipore, Bedford, USA). Buffer solutions of $\mathrm{pH} 1.2,4.5$, and 6.8 were prepared according to USP (9).

\section{Equipment}

The $\mathrm{pH}$ values of buffer solutions were measured with a Crison pH meter (model GLP 22). A UV-vis doublebeam spectrophotometer (Shimadzu UV-1700 PharmaSpec) was used. 


\section{Linearity and Sensitivity}

Linearity was determined in triplicate at the three $\mathrm{pH}$ values according to $\mathrm{ICH}$ (11). Absorbance values were recorded at wavelengths of pharmacopeial requirements: $220,221,264$, and $272 \mathrm{~nm}(9,10)$. The linearity was statistically evaluated using Statgraphics Plus v.5.1 (StatPoint Technologies, Inc., Warrenton, VA). The sensitivity was evaluated by two parameters: the slope of the calibration curve and the discriminant capacity. Discriminant capacity is defined as the smallest difference of analyte concentration that can be recorded by the method for a given probability (12).

\section{Sample Solutions}

IBU has very low solubility at acidic $\mathrm{pH}$. The maximum concentration of dissolved IBU obtained in $\mathrm{pH} 1.2$ buffer solution was $0.02 \mathrm{mg} / \mathrm{mL}$, and $0.03 \mathrm{mg} / \mathrm{mL}$ in $\mathrm{pH} 4.5$ buffer. These concentrations were considered the upper range value ( $120 \%$ of test concentration). From these stock solutions, successive dilutions were made to obtain linearity test samples in the range of $12-120 \%$ of test concentration $(0.017 \mathrm{mg} / \mathrm{mL})$ at $\mathrm{pH} 1.2$, with eight concentration levels. In the case of $\mathrm{pH} 4.5$ buffer, the range was $6-120 \%$ of test concentration $(0.025 \mathrm{mg} / \mathrm{mL})$, with six concentration levels.

In alkaline $\mathrm{pH}, \mathrm{IBU}$ is highly soluble. The maximum concentration of IBU at pH 6.8 was $0.5 \mathrm{mg} / \mathrm{mL}$. Twelve levels of dilution were evaluated, between $0.6 \%$ and $120 \%$ of test concentration $(0.42 \mathrm{mg} / \mathrm{mL})$.

\section{RESULTS AND DISCUSSION}

Results for linearity are shown in Table 1. The linear regression method was highly significant $(p<0.01)$, and the $y$-intercept did not differ from zero for all wavelengths in all cases. For gastric $\mathrm{pH}$, the slopes of the regression curves were around 0.0045 at $220 / 221 \mathrm{~nm}$. However, at 264/272 $\mathrm{nm}$ the slopes were reduced 20-fold, showing the lowest calibration sensitivity obtained for all $\mathrm{pH}$ values and wavelengths studied. At pH 4.5, all slopes were double those obtained at $\mathrm{pH} 1.2$. A 20 -fold reduction in slope value was also produced at $264 / 272 \mathrm{~nm}$ compared with that at $220 / 221 \mathrm{~nm}$. At jejunum $\mathrm{pH}$ (6.8), the slope of the method almost duplicated the slope obtained at $\mathrm{pH} 4.5$, with a large difference between the slopes at $220 / 221 \mathrm{~nm}$ and those at 264/272 $\mathrm{nm}$.

The differences among the slopes are clearly shown in Figure 1. The greatest sensitivities were obtained, in all cases, with UV measurements at $220 / 221 \mathrm{~nm}$. At those wavelengths, the range of concentrations was reduced at $\mathrm{pH} 6.8$ to conserve linearity $(0.0025-0.05 \mathrm{mg} / \mathrm{mL})$. This is a special feature of this UV method, which makes it useful for dissolution test of IBU oral suspensions, which have lower doses. A very low sensitivity method was obtained for quantification at the IBU determination wavelength specified in Ph. Eur. (264 nm), especially at acidic $\mathrm{pH}$.

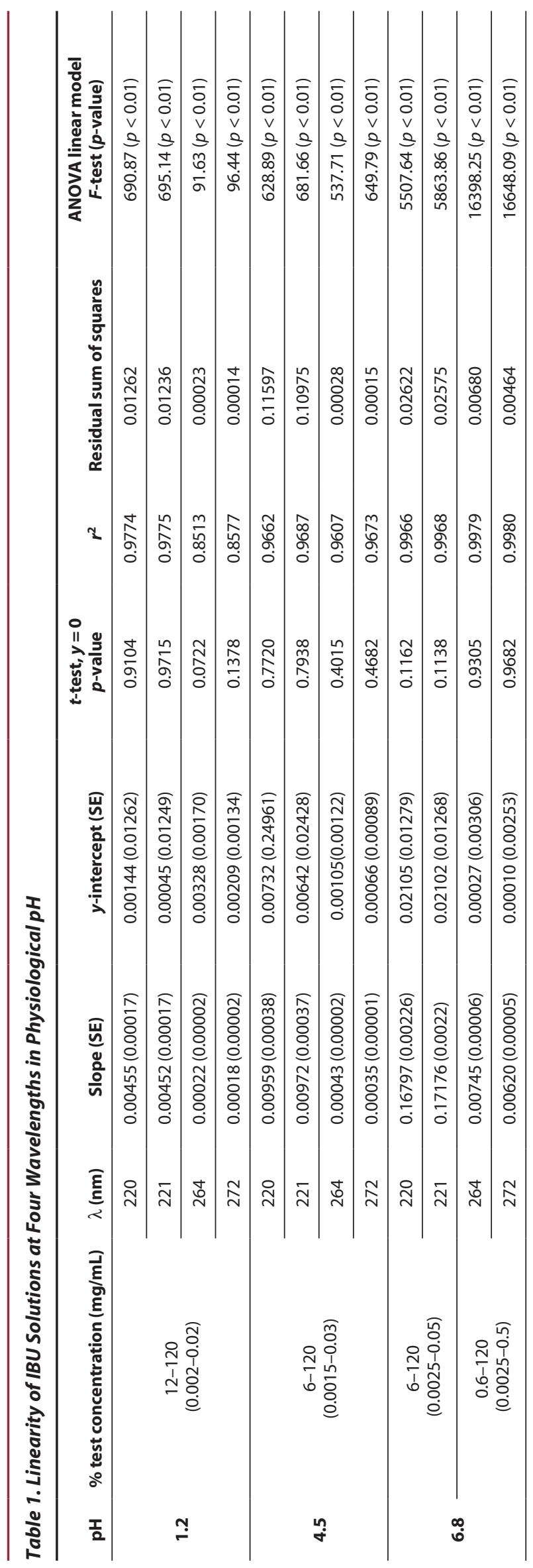

Dissolution Technologies I FEBRUARY 2013 

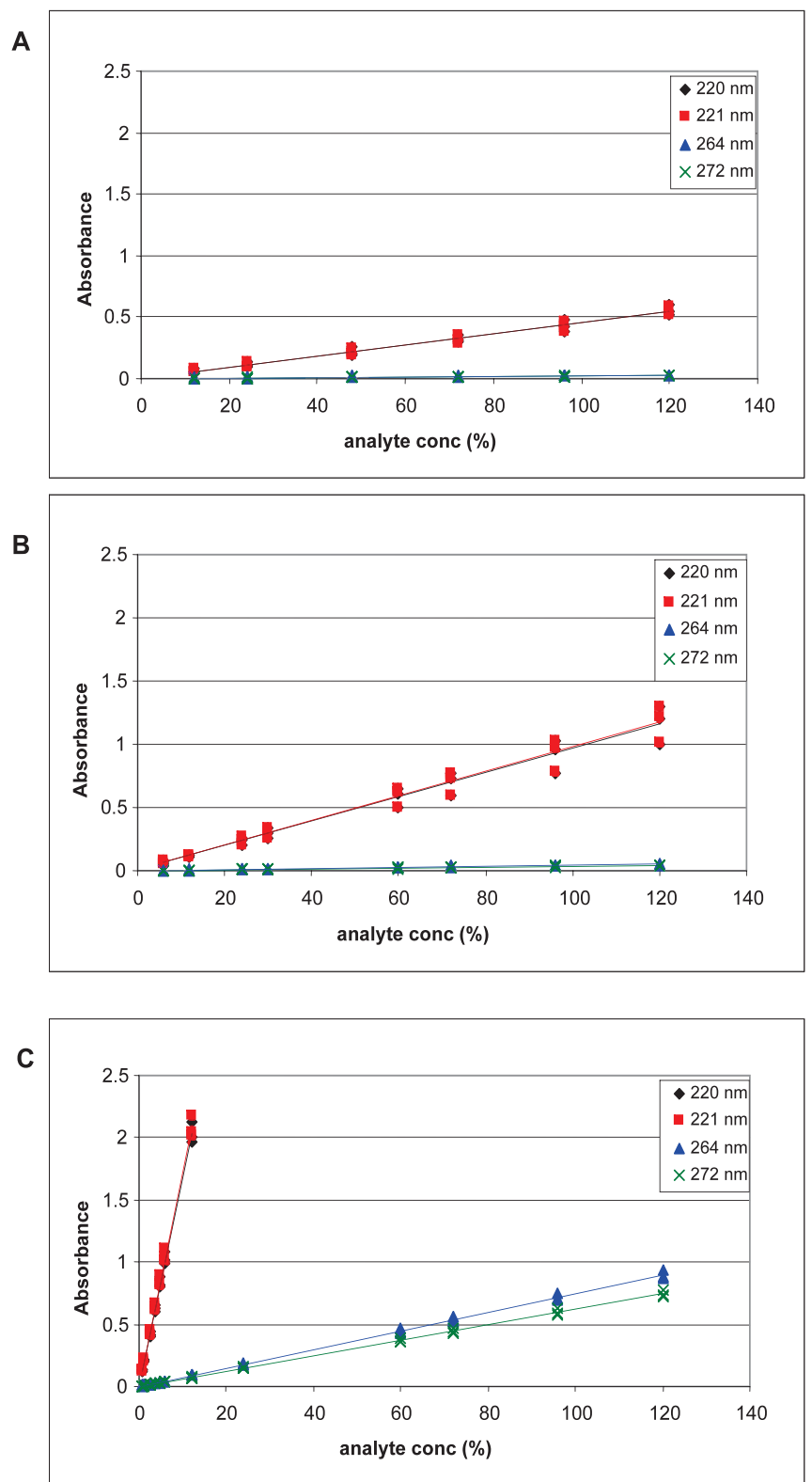

Figure 1. Sensitivity of the UV quantification method at (A) $p H$ 1.2, (B) $p H$ 4.5 , and (C) pH 6.8 at various measurement wavelengths.

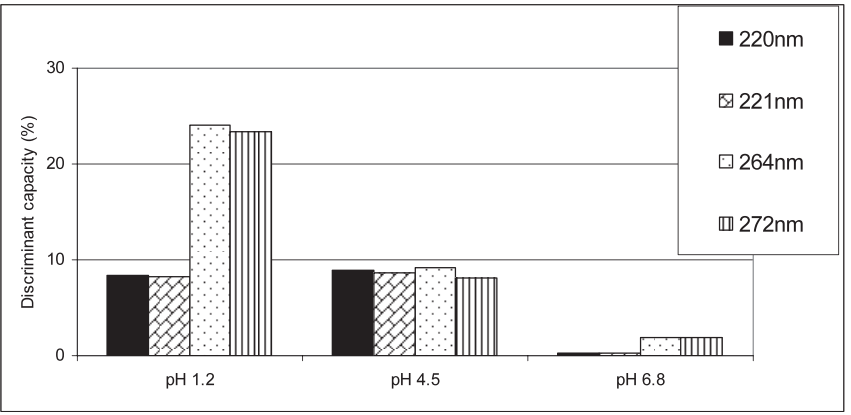

Figure 2. Discriminant capacity.
Discriminant capacity values are shown in Figure 2. For all $\mathrm{pH}$ levels studied, the smallest difference between analyte concentrations was less than $10 \%$ only at $220 / 221 \mathrm{~nm}$. This level of discrimination was sufficient to detect the minimum difference between profiles needed to obtain a similarity factor of 50 . The UV method at $264 \mathrm{~nm}$ for $\mathrm{pH} 1.2$ was not able to detect such $10 \%$ differences, because the discriminant capacity was roughly $24 \%$.

\section{CONCLUSIONS}

The highest calibration sensitivity is obtained at 220/221 nm for IBU UV measurements at the three physiological $\mathrm{pH}$ values. At the Ph. Eur. identification wavelength $(264 \mathrm{~nm})$, the UV method is not sensitive enough to detect the $10 \%$ difference between IBU concentrations required for $f_{2}$.

According to the results obtained in this work, the measurements for IBU biowaiver investigations might be carried out at 220/221 nm to obtain suitable sensitivity for discrimination between dissolution profiles.

\section{ACKNOWLEDGMENTS}

The authors would like to thank Ministerio de Educación (Argentine)-Fundación Carolina (Spain) for the postdoctoral fellowship of Dra. Noelia Gonzalez Vidal.

\section{REFERENCES}

1. Waiver of In Vivo Bioavailability and Bioequivalence Studies for Immediate-Release Solid Oral Dosage Forms Based on a Biopharmaceutics Classification System; Guidance for Industry; U.S. Department of Health and Human Services, Food and Drug Administration, Center for Drug Evaluation and Research (CDER), U.S. Government Printing Office: Washington, DC, 2000.

2. Guideline on the Investigation of Bioequivalence; CPMP/ EWP/QWP/1401/98; Committee for Medicinal Products for Human Use (CHMP); European Medicines Agency: London, 2010.

3. WHO Expert Committee on Specifications for Pharmaceutical Preparations. Multisource (generic) pharmaceutical products: guidelines on registration requirements to establish interchangeability; WHO Technical Report Series, No. 937, Annex 7; World Health Organization: Geneva, 2006; pp 347-438.

4. Polli, J. E.; Yu, L. X.; Cook, J. A.; Amidon, G. L.; Borchardt, R. T.; Burnside, B. A.; Burton, P. S.; Chen, M. L.; Conner, D. P.; Faustino, P. J.; Hawi, A. A.; Hussain, A. S.; Joshi, H. N.; Kwei, G.; Lee, V. H. L.; Lesko, L. J.; Lipper, R. A.; Loper, A. E.; Nerurkar, S. G.; Polli, J. W.; Sanvordeker, D. R.; Taneja, R.; Uppoor, R. S.; Vattikonda, C. S.; Wilding, I.; Zhang, G. Summary workshop report: Biopharmaceutics classification system-implementation challenges and extension opportunities. J. Pharm. Sci. 2004, 93 (6), 1375-1381.

5. Potthast, H.; Dressman, J. B.; Junginger, H. E.; Midha, K. K.; Oeser, H.; Shah, V. P.; Vogelpoel, H.; Barends, D. 
M. Biowaiver monographs for immediate-release solid oral dosage forms: Ibuprofen. J. Pharm. Sci. 2005, 94 (10), 2121-2131.

6. Rinaki, E.; Dokoumetzidis, A.; Valsami, G.; Macheras, P. Identification of Biowaivers Among Class II Drugs: Theoretical Justification and Practical Examples. Pharm. Res. 2004, 21 (9), 1567-1572.

7. Alvarez, C.; Nuñez, I.; Torrado, J. J.; Gordon, J.; Potthast, H.; Garcia Arrieta, A. Investigation on the possibility of biowaivers for ibuprofen. J. Pharm. Sci. 2011, 100 (6), 2343-2349.

8. Shah, V. P.; Tsong, Y.; Sathe, P.; Liu, J. P. In Vitro Dissolution Profile Comparison-Statistics and Analysis of the Similarity Factor, $f_{2}$. Pharm. Res. 1998, 15 (6), 889-896.

9. The United States Pharmacopeia and National Formulary USP 34-NF 29; The United States Pharmacopeial Convention, Inc.: Rockville, MD, 2011.
10. European Pharmacopoeia, 7th ed.; European Directorate for the Quality of Medicines \& Healthcare, Council of Europe: Strasbourg, France, 2011.

11. International Conference on Harmonisation of Technical Requirements for Registration of Pharmaceuticals for Human Use. Validation of Analytical Procedures: Text and Methodology, Q2R1; ICH Harmonised Tripartite Guideline: Geneva, Switzerland, 2005. http://www.ich.org/fileadmin/ Public_Web_Site/ICH_Products/Guidelines/Quality/ Q2_R1/Step4/Q2_R1_Guideline.pdf (accessed Jan 15, 2013).

12. Camacho, M. A.; Torres, A. I.; Gil, M. E.; Obregon, M. M.; Ruz, V. Validation protocol of analytical methods for finished pharmaceutical products. STP Pharma Pratiques 1993, 3 (3), 197-202. 